\title{
Politique
}

Politique

Réal Bélanger, L'impossible défi-Albert Sévigny et les

conservateurs fédéraux (1902-1918), Québec, Les Presses de

l'Université Laval, coll. Les Cahiers d'histoire, 1983, 368 p.

\section{Michel Martin}

Numéro 6, automne 1984

La réforme des institutions politiques

URI : https://id.erudit.org/iderudit/040468ar

DOI : https://doi.org/10.7202/040468ar

Aller au sommaire du numéro

Éditeur(s)

Société québécoise de science politique

ISSN

0711-608X (imprimé)

1918-6584 (numérique)

Découvrir la revue

Citer ce compte rendu

Martin, M. (1984). Compte rendu de [Réal Bélanger, L'impossible défi-Albert Sévigny et les conservateurs fédéraux (1902-1918), Québec, Les Presses de l'Université Laval, coll. Les Cahiers d'histoire, 1983, 368 p.] Politique, (6), 181-186. https://doi.org/10.7202/040468ar d'utilisation que vous pouvez consulter en ligne.

https://apropos.erudit.org/fr/usagers/politique-dutilisation/ 
Réal Bélanger, L'impossible défi - Albert Sévigny et les conservateurs fédéraux (1902-1918), Québec, Les Presses de l'Université Laval, coll. Les Cahiers d'histoire, 1983, 368 p.

Si les hommes politiques canadiens-français (ou plus précisément québécois) œuvrant sur la scène fédérale ont, de tout temps, éprouvé un certain nombre de difficultés à concilier défense des aspirations de leurs concitoyens francophones, minoritaires au Canada, et promotion des intérêts nationaux (ou de leur carrière personnelle), que dire de la performance, à ce chapitre, des conservateurs québécois? Longtemps perçu par une grande majorité de Québécois francophones comme un parti «d'orangistes et de mangecanayens", le parti conservateur n'a jamais vraiment pu s'implanter au Québec et les téméraires qui osaient s'engager sous cette étiquette devaient, en plus du dilemme soulevé plus tôt, se tailler une place entre la sous-estime que les chefs anglophones du parti conservateur éprouvaient à leur endroit et l'incompréhension, voire même le rejet, de leurs compatriotes francophones.

Fort bien documenté, d'un esprit critique évident et rempli d'anecdotes aussi intéressantes les unes que les autres, particulièrement en ce qui concerne les mœurs électorales d'antan, l'ouvrage de Réal Bélanger se penche sur les mésaventures politiques de l'un de ces téméraires du début du siècle: Albert Sévigny. Constatant, avec raison, les lacunes historiographiques entourant le début du siècle et déplorant surtout l'oubli auquel sont voués trop d'hommes politiques qui, en dehors de Laurier, Gouin et Bourassa, ont quand même joué un rôle de premier plan à cette époque dramatique de l'histoire canadienne, l'auteur désire nous faire partager les péripéties de l'un de ces politiciens que l'histoire avait jusque là ignoré et dont les choix furent lourds de conséquences et pour sa carrière politique et pour le parti conservateur pendant les trente ans qui suivirent. 
Étude à caractère biographique, ce livre de Réal Bélanger retrace la carrière politique tumultueuse d'Albert Sévigny qui s'échelonne sur une période de seize ans, soit de 1902, année où il apparaît pour la première fois en public jusqu'à mars 1918 alors qu'il remet sa démission comme Ministre du Revenu de l'Intérieur. Cette recherche est intéressante et captivante à plusieurs points de vue. En effet, la carrière politique d'Albert Sévigny est intimement liée aux grands événements socio-politiques des deux premières décennies du $\mathrm{XX}^{\mathrm{e}}$ siècle. De plus, cette reconstitution historique autour du personnage d'Albert Sévigny permet à l'auteur de dégager certaines conclusions quant à l'évolution des deux grands partis politiques fédéraux au Québec, en particulier celle du parti conservateur auquel Sévigny adhère alors que s'affrontent, tant au sein du parti lui-même que dans la société canadienne en général, les deux grands courants: le nationalisme et l'impérialisme. Personnage controversé, Albert Sévigny sera constamment tiraillé, déchiré entre ses ambitions personnelles et ses prises de positions contradictoires et ambiguës qui finalement causeront sa perte au moment où les deux peuples fondateurs sont profondément divisés au sujet de la conscription.

Réal Bélanger brosse tout d'abord un tableau sommaire mais fort pertinent de l'état de la situation économique et politique qui prévaut à l'aube du $\mathrm{XX}^{\mathrm{e}}$ siècle. S'il est exact de constater que le Canada et le Québec connaissent une expansion sans précédent au plan économique, le système politique canadien, par contre, semble toujours sous l'emprise d'un bipartisme de moins en moins flexible et quiconque songe à faire carrière en politique doit inévitablement gravir les échelons à l'intérieur de l'une ou l'autre des formations politiques en présence (le parti libéral et le parti conservateur) et ce, en sacrifiant plus souvent qu'autrement ses convictions personnelles, sans quoi il est condamné à la marginalité et à l'isolement complet. Toutefois, la situation politique au Québec permet d'entrevoir un changement d'attitude à cet égard. 
Depuis 1896, Laurier et le parti libéral règnent en rois et maîtres sur la "Belle Province" ayant pour seule opposition un parti conservateur désorganisé, miné par les dissensions internes et dont les chances de se renouveller sont inversement proportionnelles à la présence de ceux que l'on a baptisé les «castors» (membres d'une arrière-garde au conservatisme étroit qui domine le parti à cette époque). Tout porte à croire que seule une autre formation politique susceptible de représenter ce nouvel esprit qui anime le Canada français soit en mesure d'ébranler la forteresse libérale au Québec. En effet, ce nationalisme qui s'exprime au Québec - fondé sur le sentiment que le Canada ne s'affirmera pleinement qu'à l'extérieur de l'empire britannique - va à l'encontre du souhait largement partagé au Canada anglais selon lequel le pays doit plutôt resserrer ses liens avec l'empire. Pris entre deux feux, Laurier décide néanmoins de supporter l'Angleterre dans la guerre des Boers et provoque la colère de son député de Labelle, Henri Bourassa, qui deviendra au Québec le symbole de la lutte antiimpérialiste. Si les deux hommes se réconcilient par la suite, Laurier sait maintenant mieux que tout autre le tort que pourrait lui causer Bourassa, chef de file des nationalistes, dans l'éventualité d'une nouvelle croisade anti-impérialiste.

Voilà donc tracés les paramètres à l'intérieur desquels devra manœuvrer Albert Sévigny s'il veut se tailler une place confortable sur l'échiquier politique québécois et dans la faveur populaire. À première vue, on peut s'interroger sur l'opportunité du choix d'Albert Sévigny de joindre les rangs du parti conservateur; pour un jeune homme qui aspire aux plus hautes distinctions politiques, force nous est de constater que le choix n'est pas des plus judicieux. Mais, comme le démontre l'auteur, il semble que cette décision soit davantage le fruit de l'influence familiale, traditionnellement d'allégeance tory, que d'une analyse poussée de la situation politique. En fait, ce n'est que lorsqu'il commencera à «analyser l'évolution politique» dans la province que les choses se compliqueront pour 
lui. Ainsi, sa carrière se traduira de la façon suivante: la première phase, conservatrice (1902-1908), l'autre, conservatrice-nationaliste (1909-1913) et enfin, le retour aux sources conservatrices (19131918)... avec les avantages et tous les inconvénients que cela comporte!

Nonobstant sa participation à l'élection fédérale partielle dans le comté de Beauharnois en 1902 alors qu'il prend contact avec la réalité conservatrice au Québec - à savoir, la défaite , sa carrière proprement dite débute, aux dires de l'auteur, lorsqu'il arrive à Québec pour y faire ses études de droit. Si ses premiers pas en politique sont plutôt modestes, son ascension au sein du parti conservateur est néanmoins constante et rapide, si bien qu'en peu de temps, il est identifié comme le chef de file des jeunes conservateurs. Les défaites électorales et les règlements de comptes, propres au parti, ne semblent pas atténuer sa ferveur pour cette formation politique et le discours qu'il prononce aux côtés du chef du parti, Robert L. Borden, à l'été de 1907, constitue le tremplin tant attendu pour se lancer dans l'arène électorale. $\grave{A}$ l'instar du parti, Sévigny subira la défaite lors de l'élection provinciale partielle dans Nicolet. Même s'il représente désormais un élément d'espoir pour le parti, les dissensions persistantes entre les jeunes et les «castors», amplifiées par deux revers électoraux en 1908, sont de nature à démoraliser ce jeune politicien.

Début 1909, l'alliance conservatrice-nationaliste à l'Assemblée législative s'avère très fructueuse pour les conservateurs québécois. Voyant la conjoncture politique évoluer sous l'impulsion du mouvement nationaliste, Albert Sévigny en vient à la conclusion que l'avancement de sa carrière personnelle passe nécessairement par un rapprochement avec ce mouvement que dirige Henri Bourassa. Ce n'est qu'en 1910, toutefois, que se concrétisera ce rapprochement alors que Sévigny entreprend avec les nationalistes une tournée du Québec pour dénoncer le projet fort controversé de «la marine Laurier". Se déclarant résolument autonomiste, il se présente sous 
l'étiquette conservatrice-nationaliste aux élections fédérales de 1911. Le soir de l'élection, il est élu député de Dorchester et réalise ainsi l'un de ses rêves les plus chers.

Malgré l'élection de 17 conservateurs-nationalistes au Québec, le poids politique de cette alliance est négligeable à Ottawa. Évincé du premier cabinet Borden, Sévigny doit réajuster son tir s'il veut réaliser son ambition d'accéder au cénacle ministériel; c'est ainsi que, petit à petit, il se fait l'ardent promoteur des politiques du gouvernement Borden malgré les critiques acerbes qui s'abattent sur lui. Le 4 août 1914, lorsque Borden apprend que l'Angleterre est en guerre contre l'Allemagne, Albert Sévigny est conscient que le pays, le parti conservateur ainsi que sa propre carrière s'engagent dans un tournant historique dont il ignore encore tout de l'issue. Début 1917, alors qu'il vient tout juste d'être nommé ministre du Revenu de l'Intérieur, consécration ultime de sa carrière politique, le voilà confronté à la décision de Borden d'imposer la conscription. Plutôt que de démissionner, il appuie son chef d'un retentissant "J'accepte» lors du débat en Chambre, conscient qu'il se suicide politiquement et que son parti est rayé de la carte politique québécoise pour les vingt-cinq ou trentes prochaines années.

Il va sans dire que la carrière d'Albert Sévigny constitue le parfait exemple à ne pas suivre. Considéré par l'historien nationaliste Lionel Groulx comme «un traître à sa race» et par ceux qui l'ont connu comme «un homme qui n'a pas tenu sa parole», Albert Sévigny ne représente cependant pas un cas isolé lorsqu'il s'agit de ne pas respecter ses engagements. En effet, le dernier mandat du gouvernement libéral à Ottawa a permis de démontrer hors de tout doute que certains politiciens étaient capables d'en faire autant sinon plus et ce, de manière plus subtile, sans toutefois subir le quart du traitement réservé à Sévigny... Autres temps, autres mœurs, dit-on! Mais ce qu'il importe plus particulièrement de remarquer, environ soixante-dix ans après cette triste fin de 
carrière, c'est que chaque regain de vie des conservateurs au Québec, sur le plan électoral, est le fruit d'un curieux mélange de vieux conservateurs et de nationalistes, décidés à se débarasser d'un groupe de libéraux depuis trop longtemps assis sur le Québec; c'est ce qui s'est produit en 1911, en 1958 et de même, le 4 septembre dernier. De plus, n'ayant pas su s'adapter au pouvoir ainsi qu'aux idées de leurs collègues anglophones, nos députés conservateurs revenaient bredouilles quatre ans plus tard, ne semblant avoir tiré aucune leçon de l'expérience. Mais avec à sa tête, pour la première fois dans l'histoire du parti, un Québécois d'origine irlandaise, bilingue et biculturel et marié à une Yougoslave si cet alliage vous paraît étrange, pensez à progressiste-conservateur... - la délégation québécoise pourrait peut-être, cette fois-ci, se révéler moins éphémère.

Michel Martin

Université Laval 